\title{
Association Between Random Glucose Level and Leukocytes Count in Female Cancer Patients
}

\author{
Mazen M. Almehmadi ${ }^{1}$ \\ 1. Clinical Laboratory, Taif University, Taif, SAU
}

Corresponding author: Mazen M. Almehmadi, dr.mazen.ma@gmail.com

\begin{abstract}
Leukocytosis is common among patients suffering from cancer when leukocytes count exceeds 11,000 cells per $\mathrm{mm}^{3}$. This is a usual immune response toward infection and foreign elements. This leads to the release of inflammatory mediators at the targeted site. Studies have found leukocytes count increase in diabetes mellitus patients. Random glucose level indicates the patient is at risk of developing diabetes mellitus. In this study, the association between random glucose level and leukocytes count in female cancer patients is evaluated. About 210 cancer patients included in this study and the results have indicated a positive association between high glucose level and high leukocyte count. This indicates poor prognosis of the patients as high glucose levels increase tumor cell proliferation and high leukocytes count can induce inflammation leading to the progression of cancer and increase mortality rate.
\end{abstract}

Received 06/13/2020

Review began 06/24/2020 Review ended 06/25/2020 Published 07/02/2020

() Copyright 2020

Almehmadi. This is an open access article distributed under the terms of the Creative Commons Attribution License CC-BY 4.0., which permits unrestricted use, distribution, and reproduction in any medium, provided the original author and source are credited.
Categories: Allergy/Immunology, Oncology, Hematology

Keywords: uterine cervical cancer, endometrial carcinoma, cancer, leukocytes, leukocytosis, breast cancer, gastrointestinal cancer, female genital tract cancer

\section{Introduction}

The mortality rate due to cancer is high worldwide. Leukocytes have a major role in immune system response against cancer as they recognize and infiltrate tumors [1]. Expansion of leukocytes in the blood is defined as leukocytosis and upon activation, they well release several inflammatory mediators. Normal level of white blood cells (WBC) is different and age-dependent, the normal level in adults is 4500 to 11000 cells per $\mathrm{mm}^{3}$; this level is higher in infant and pregnant females [2,3]. A study has recommended that reference range for leukocytes count should be set according to the laboratory specific analyzer. This is due to different validation processes [2]. Leukemoid reaction is a phenomenon that occurs due to factors such as infection and solid tumor formation, and it is defined as when leukocyte numbers expand to reach 50,000 up to 100,000 cells per $\mathrm{mm}^{3}[3,4]$. The involvement of bone marrow or high levels of a granulocyte-colonystimulating factor (G-CSF) can induce leukocytes expansion [3,5]. Leukocytosis is detected in solid tumor patients which can lead to severe complications. The expansion of leukocytes can reach levels of leukemoid reaction between 50,000 to 100,000 per $\mathrm{mm}^{3}$ which can lead to an inflammatory response [3,5]. Human papillomavirus (HPV) is the main etiological factor of cervical cancer, and experimental models with HPV-positive models have shown high recruitment of leukocytes toward these cell lines [6]. Various studies have detected several abnormalities in hematological patterns in cancer patients. Leukocytosis was detected in patients with solid tumors according to a study that detected anemia and thrombocytosis as well [7]. Leukocytosis was also detected in non-small cell lung carcinoma [8]. Moreover, it was also detected in colorectal cancer patients which also accompanied by dehydration and malnutrition [9]. Another study has reported leukocytosis with anal cancer patients, which can assist in predicting possible relapse after treatment [10]. Leukocytosis was also correlated with increase mortality rate when co-existing with thrombosis [11].

Diabetes mellitus (DM) impact on health is thoroughly studied and documented. Glucose intolerance and chronic complications of DM are associated with an expansion of leukocytes number, which can also advance and cause nephropathy $[12,13]$. In this study, an investigation about the association between glycemic status and leukocytes number in cancer patients was conducted.

\section{Materials And Methods}

\section{Study design}

This retrospective study was approved by the directorate of health affairs in Taif city for the period of 2018 to 2019; a consent form was provided. Firm inclusion measures were applied to include the data in the study. Firstly, patients in the study diagnosed with any type of cancer at King Faisal Hospital (KFH) between 2018 and December of 2019; secondly, only female cancer patients were included; thirdly, they had a measurement of both glucose levels and leukocytes count. The number of recruited participants in this research was 210 . 


\section{Cureus}

\section{Samples analysis}

When patients were requested to provide biopsy samples, a minimum of $3 \mathrm{~mL}$ of venous blood was collected, analyzed freshly, and not stored through ROCHE COBAS ${ }^{\circledR}$ platform e501. Patients were advised to fast for 10 hours before collecting the blood. This study collected the following information: age of the patient, type of diagnosed cancer, glucose level, and WBC count.

\section{Statistical analysis}

Microsoft excel for office was used for sorting of data, calculating frequencies, percentage, standard deviation $(\sigma)$, chi-square analysis to compare frequencies, and one-way ANOVA was used to compared means. Results when P-value $<.05$ were considered significant.

\section{Results}

\section{Demographic analysis}

The number of participants in this study was 210 female patients from 2018 to December 2019. The youngest participant's age was 13 years and the oldest was 108 years old. All those patients were living in Taif. All study participants were females who were confirmed to develop malignant tumor (Table 1).

\begin{tabular}{|c|c|c|c|c|}
\hline & \multicolumn{3}{|l|}{ Age groups } & \multirow{2}{*}{ Total } \\
\hline & $<40$ & $40-64$ & $>64$ & \\
\hline Number of participants & 36 (17.14\%) & 125 (59.52\%) & 49 (23.34\%) & \multirow{2}{*}{210} \\
\hline Mean \pm SD & $33 \pm 6$ & $53 \pm 6.8$ & $75 \pm 9$ & \\
\hline
\end{tabular}

TABLE 1: Participants are distributed into three groups according to their age.

SD: Standard deviation

\section{Frequencies of cancer types}

The type of cancer of this study patients is illustrated in Table 2. Most patients were breast cancer patients and about $80 \%$ of the cases were invasive duct carcinoma patients, followed by female genital tract cancer patients, about $63 \%$ of them were endometrial carcinoma, followed by $22.22 \%$ cervical cancer. Gastrointestinal tract cancer patients were $16.5 \%$, and $28.57 \%$ of those were sigmoid cancer patients, and $25.71 \%$ diagnosed with rectal mass cancer. Head and neck cancer patients were $9.43 \%$, the highest percentage of patients (65\%) were diagnosed with thyroid cancer. All urinary tract patients were diagnosed with bladder cancer. Blood tumor patients were only $3.3 \%$ and skin cancer $1.41 \%$.

\begin{tabular}{|c|c|c|c|}
\hline Туре & Diagnosis & Number of cases & \% by type \\
\hline \multirow{6}{*}{ Breast cancer (BC) } & Invasive duct carcinoma & 65 & 80.24 \\
\hline & Invasive lobular carcinoma & 10 & 12.34 \\
\hline & Invasive micropapillary carcinoma & 2 & 2.46 \\
\hline & Invasive mammary carcinoma & 2 & 2.46 \\
\hline & Mucinous adenocarcinoma & 1 & 1.23 \\
\hline & In situ duct carcinoma (comedocarcinoma) & 1 & 1.23 \\
\hline \multirow{6}{*}{ Female genital tract cancer (FGT) } & Endometrial carcinoma & 34 & 62.96 \\
\hline & Cervical cancer & 12 & 22.22 \\
\hline & Uterus with bilateral fallopian tube & 3 & 5.55 \\
\hline & Uterine carcinoma & 2 & 3.70 \\
\hline & Left ovarian cyst & 2 & 3.70 \\
\hline & Anterior vaginal wall & 1 & 1.85 \\
\hline
\end{tabular}




\section{Cureus}

\begin{tabular}{|c|c|c|c|}
\hline \multirow{11}{*}{ Gastrointestinal tract cancer (GIT) } & Sigmoid cancer & 10 & 28.57 \\
\hline & Rectal cancer & 9 & 25.71 \\
\hline & Colon cancer & 5 & 14.28 \\
\hline & Caecum cancer & 2 & 5.71 \\
\hline & Hepatocellular carcinoma & 2 & 5.71 \\
\hline & Adenocarcinoma of rectosigmoid & 1 & 2.85 \\
\hline & Ascending colon cancer & 1 & 2.85 \\
\hline & Duodenal cancer & 2 & 5.71 \\
\hline & Esophageal cancer & 1 & 2.85 \\
\hline & Gastric mucosal cancer & 1 & 2.85 \\
\hline & Hyperplastic polyp & 1 & 2.85 \\
\hline \multirow{6}{*}{ Head and neck cancer (H\&N) } & Thyroid cancer & 13 & 65 \\
\hline & Tubulovillous adenoma & 3 & 15 \\
\hline & Hurthle cell adenoma & 1 & 5 \\
\hline & Nasopharyngeal cancer & 1 & 5 \\
\hline & Palate cancer & 1 & 5 \\
\hline & Tongue carcinoma & 1 & 5 \\
\hline Urinary tract cancer (UTI) & Bladder cancer & 10 & 100 \\
\hline \multirow{7}{*}{ Blood tumor (BT) } & Spindle cell tumor & 2 & 28.57 \\
\hline & Multiple myeloma & 1 & 14.28 \\
\hline & Hodgkin's lymphoma & 1 & 14.28 \\
\hline & Left axillary lymph nodes & 1 & 14.28 \\
\hline & Non-Hodgkin's lymphoma & 1 & 14.28 \\
\hline & Right inguinal lymph node & 1 & 14.28 \\
\hline & Right axillary lymph node & 1 & 14.28 \\
\hline \multirow{3}{*}{ Skin cancer (SC) } & Skin, subcutaneous left cheek cancer & 1 & 33.33 \\
\hline & Skin from right gluteal region cancer & 1 & 33.33 \\
\hline & Scalp cancer & 1 & 33.33 \\
\hline
\end{tabular}

TABLE 2: Frequency of cancer patients are distributed according to the tissue and diagnoses.

Association between random glucose levels (RGL) and leukocyte count

RGL was associated with leukocytes number. The levels of RGL were divided into four groups, and the mean levels of leukocytes number from all patients were calculated (Figure 1). The RGL was divided into $<70,70$ to 150,150 to 200, and $>200$ and compared by applying one-way ANOVA test. Significantly the highest mean of leukocytes number among all patients' groups were those with RGL 150 to 200, followed by >200, 70 to 150 , and the lowest group with <70 (P-value .0208). 


\section{Cureus}

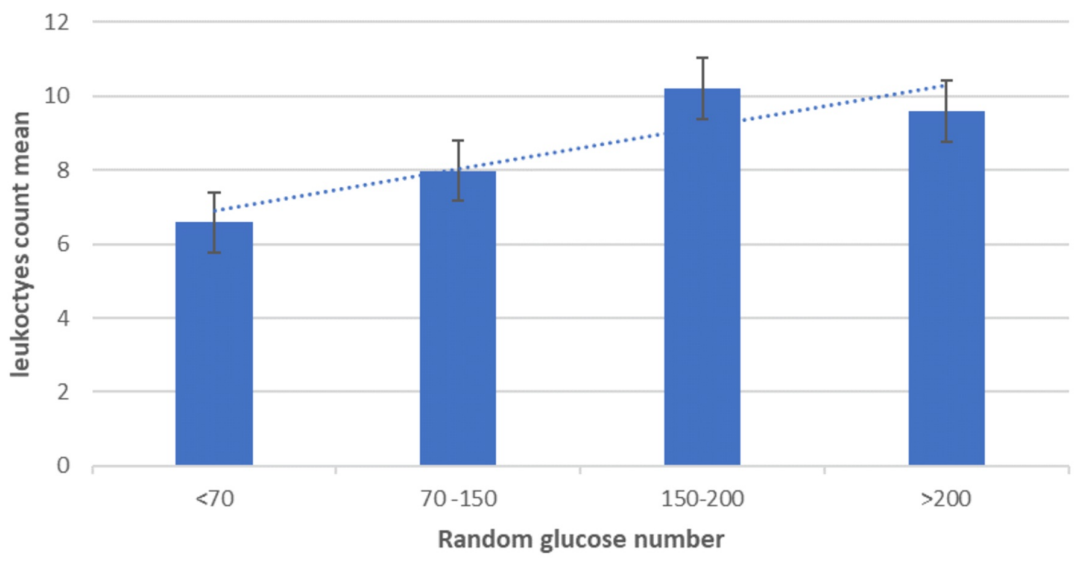

FIGURE 1: In the bar-graph, the mean of leukocytes count is positively increasing in association with the increase in RGL concentration in the blood. The lowest level is in $<70$ RGL group (P-value .0208).

RGL: Random glucose levels

Leukocytes count $\mathrm{K} / \mathrm{uL}(\mathrm{K}=1000)$

Number of $<70=12$, Number of $70-150=154$, Number of $150-200=22$, Number of $>200=22$.

In Table 3, the association between RGL and leukocytes count is illustrated. According to age groups, in $<40$ years, significantly $80.5 \%$ are having normal leukocytes number, $11.12 \%$ having leukocytosis, and $8.3 \%$ having leukopenia. In 40 to 64 years, $80.62 \%$ of the patients are significantly showing normal leukocytes number, followed by $12.4 \%$ having leukocytosis and $4 \%$ having leukopenia. The hyperglycemic patients $(69.23 \%)$ in this age group are significantly showing normal levels of leukocytes, $23.07 \%$ showing leukocytosis, and $7.7 \%$ showing leukopenia. For the age group $>64$ years, significantly $77.55 \%$ patients are showing normal levels of leukocytes, $12.23 \%$ showing leukocytosis, and $10.2 \%$ showing leukopenia. The hyperglycemic patients (66.66\%) in this age group are showing significantly normal levels and $33.33 \%$ showing leukocytosis.

\begin{tabular}{|c|c|c|c|c|c|c|c|c|}
\hline \multicolumn{3}{|c|}{ Characteristics } & $\begin{array}{l}\text { Number of } \\
\text { cases }\end{array}$ & $\begin{array}{l}\text { Leukocytes mean } \\
\pm S D\end{array}$ & $\begin{array}{l}\text { Leukocytosis } \\
(\%)\end{array}$ & $\begin{array}{l}\text { Normal } \\
(\%)\end{array}$ & $\begin{array}{l}\text { Leukopenia } \\
\text { (\%) }\end{array}$ & P-value \\
\hline \multirow{9}{*}{ Age groups } & \multirow{3}{*}{$<40$} & All & 36 & $7.95 \pm 3.35$ & 4 (11.12) & 29 (80.5) & $3(8.3)$ & 0.00001 \\
\hline & & Hyperglycemic & 3 & $9.72 \pm 6.04$ & $2(66.66)$ & 0 & $1(33.33)$ & 0.36787 \\
\hline & & Hypoglycemic & 3 & $8.21 \pm 1.09$ & 0 & $3(100)$ & 0 & 0.05178 \\
\hline & \multirow{3}{*}{$\begin{array}{l}40- \\
64\end{array}$} & All & 125 & $8.35 \pm 3.94$ & $16(12.8)$ & 104 (83.2) & $5(4)$ & 0.00001 \\
\hline & & Hyperglycemic & 26 & $9.54 \pm 3.54$ & $6(23.07)$ & $18(69.23)$ & $2(7.7)$ & 0.00003 \\
\hline & & Hypoglycemic & 1 & - & 0 & $1(100)$ & 0 & 0.36787 \\
\hline & \multirow{3}{*}{$>64$} & All & 49 & $8.39 \pm 4.5$ & 6 (12.24) & 38 (77.55) & $5(10.2)$ & 0.00001 \\
\hline & & Hyperglycemic & 12 & $12.29 \pm 6.69$ & 4 (33.33) & $8(66.66)$ & 0 & 0.0183 \\
\hline & & Hypoglycemic & 2 & $4.67 \pm 0.41$ & 0 & $1(50)$ & $1(50)$ & 0.6065 \\
\hline & \multirow{3}{*}{ BC } & All & 81 & $7.65 \pm 3.38$ & $4(5)$ & $69(86.25)$ & 7 (8.75) & 0.00001 \\
\hline & & Hyperglycemic & 12 & $8.03 \pm 4.22$ & $1(8.33)$ & $9(75)$ & 2 (16.66) & 0.00865 \\
\hline & & Hypoglycemic & 2 & $4.2 \pm 0.12$ & 0 & $2(100)$ & 0 & 0.1353 \\
\hline & \multirow[b]{2}{*}{ FGI } & All & 54 & $8.91 \pm 2.72$ & $11(20.37)$ & 41 (75.9) & $2(3.7)$ & 0.00001 \\
\hline & & Hyperglycemic & 9 & $10.5 \pm 2.63$ & $2(22.22)$ & $7(77.77)$ & 0 & 0.0131 \\
\hline
\end{tabular}




\section{Cureus}

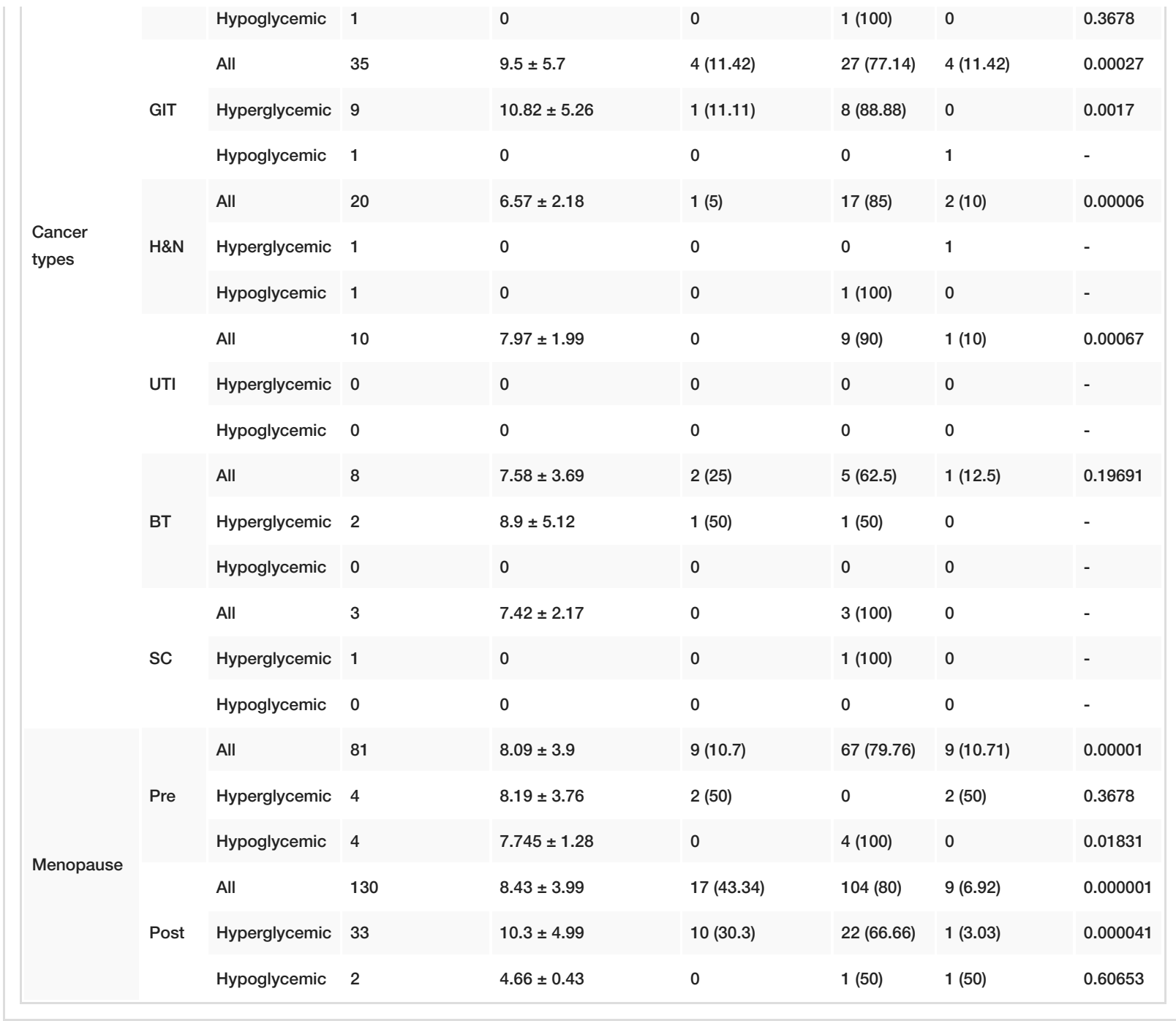

TABLE 3: Association between RGL and leukocyte count is identified according to age, cancer type, and menopause status.

Leukocytes mean K/uL

BC: Breast cancer; FGT: Female genital tract; GIT: Gastrointestinal tract; H\&N: Head and neck; UTI: Urinary tract infection; BT: Blood tumor; SC: Skin cancer.

Evaluation of the association according to the cancer type has shown the following: in breast cancer, the highest group has shown normal leukocytes number in all patients and hyperglycemic patients, followed by leukopenia in all patients group and hyperglycemic patients group. In female genital tract cancer patients, $75.9 \%$ patients showed normal leukocytes count and $20.37 \%$ showed leukocytosis. In the hyperglycemic group, $77.77 \%$ showed normal leukocytes count and $22.22 \%$ showed leukocytosis. In gastrointestinal tract cancer patients, significantly $77.14 \%$ patients showed normal leukocytes count and $88.88 \%$ hyperglycemic patients showed normal leukocytes count. In the head and neck group, significantly $85 \%$ patients showed normal leukocytes count. In the urinary tract patients, significantly $90 \%$ patients showed normal leukocytes count. No leukocytosis was detected in all hypoglycemic patients.

Furthermore, menopause status was associated according to RGL and leukocytes count. Significantly, $79.76 \%$ premenopausal cancer patients showed normal leukocytes number, and the same percentage of the patients showed leukocytosis and leukopenia. In post-menopausal cancer patients, $80 \%$ showed normal leukocytes number, followed by $13 \%$ with leukocytosis and $7 \%$ with leukopenia. Hyperglycemic patients were $66.66 \%$ with normal leukocytes number and $30.3 \%$ with leukocytosis.

In Figure 2, further study about leukocytosis in cancer groups has shown a positive increase in leukocytes count with the increase in RGL in invasive duct carcinoma (IDC), endometrial carcinoma (EC), cervical cancer (CC), and sigmoid cancer (P-value 0.0001). Sigmoid cancer has the highest leukocytosis among the 


\section{Cureus}

rest of the types.

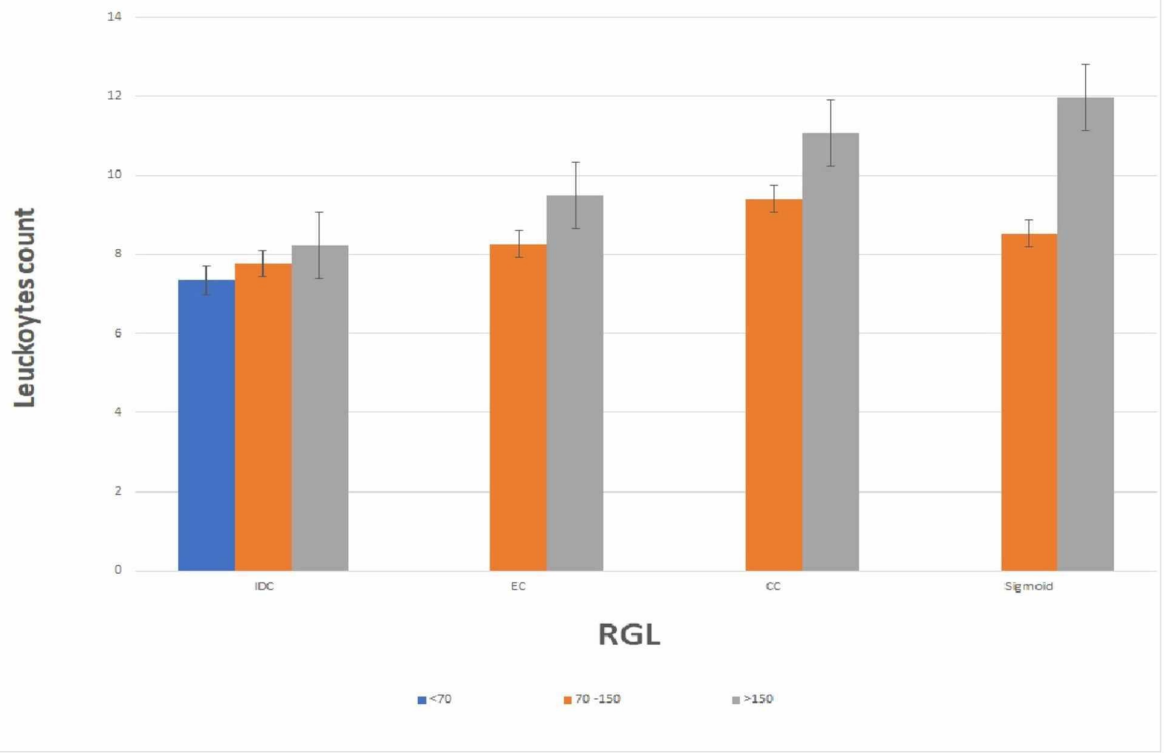

FIGURE 2: Leukocytes count increases positively with the increase in RGL in blood, highest leukocytes count when >150 RGL (P-value .00001).

RGL: Random glucose levels

Leukocytes k/uL

Number of Invasive duct carcinoma (IDC) $<70=4,70$ to $150=50,>150=11$

Endometrial carcinoma (EC) 70 to $150=26,>150=8$

Cervical cancer (CC) 70 to $150=9,>150=3$

Sigmoid 70 to $150=7,>150=3$.

\section{Discussion}

High glucose levels can increase the proliferation rate of tumor cells. Inflammation is an immune response detected due to infection and tumor development. One of the important features used for diagnoses is inflammation due to tumor-infiltration by leukocytes, where they assist by releasing of several inflammatory mediators. Leukocyte count is a common and affordable test. And it assists in diagnoses, especially in cancer patients. This study has investigated the association between leukocytes count and RGL in female cancer patients. Leukocytes count was higher in those with RGL $>150 \mathrm{mg} / \mathrm{dL}$, and the lowest count was detected in those with RGL $<70 \mathrm{mg} / \mathrm{mL}$. These findings are consistent with another study, though they have stated that this elevation is an association with a defect in glucose metabolism [14]. Another study demonstrated that cancer mortality is associated with elevation in leukocytes count, where it has reported that this mortality rate is independent of DM, and fasting glucose level [15]. One study found an elevation in leukocytes count before and after the treatment of lung cancer [16]. About $43 \%$ of post-menopausal cancer patients have developed leukocytosis, and $30.3 \%$ of them are hyperglycemic which was reported by other studies in breast cancer patients and ovarian carcinoma [17,18]. Leukocytosis was higher in patients $>40$ years old, and especially in post-menopausal females. A study performed by Connolly et al. has detected leukocytosis in several cancer types such as in breast cancer, gastric and pancreatic cancer, lung cancer, and blood cancer [11]. That is consistent with this study findings as leukocytosis was found in $50 \%$ of blood tumor patients, $5 \%$ of breast cancer patients, where $8 \%$ was hyperglycemic, $4 \%$ was gastrointestinal tract cancer patients and $11.11 \%$ were hyperglycemic. In head and neck cancer patients, leukocytosis was found in $5 \%$ of the patients. Squamous cell carcinoma is frequent in head and neck cancer due to factors such as human papillomavirus (HPV) [19]. Many studies have reported leukocytosis in head and neck cancer patients [20]. In female genital tract patients, about $20 \%$ had leukocytosis, and $22.22 \%$ of hyperglycemic patients had leukocytosis. In female genital tract cancers, leukocytosis is a major prognostic to evaluate survival rates, such as in cervical cancer and endometrial cancer [21-23]. 


\section{Conclusions}

In conclusion, in this study leukocytosis was positively associated with RGL in female cancer patients. A total of 210 female cancer patients were included in this study with the majority of them showing normal leukocytes count. All hypoglycemic cancer patients did not develop leukocytosis. A significant percentage of hyperglycemic cancer patients developed leukocytosis which is evident that high RGL can lead to an increase in leukocytes count in cancer patients. Leukocytosis was reported to be associated with recurrence of cancer, and this study has detected RGL is also associated with leukocytosis. The recurrence can occur at any time after the treatment. Therefore, the management of glucose levels in these patients is essential.

\section{Additional Information \\ Disclosures}

Human subjects: Consent was obtained by all participants in this study. Directorate of Health Affairs in Taif city issued approval HAP-02-T-067. I confirm this study has been approved by the directorate of health affairs in Taif city and the approval number is provided. Animal subjects: All authors have confirmed that this study did not involve animal subjects or tissue. Conflicts of interest: In compliance with the ICMJE uniform disclosure form, all authors declare the following: Payment/services info: All authors have declared that no financial support was received from any organization for the submitted work. Financial relationships: All authors have declared that they have no financial relationships at present or within the previous three years with any organizations that might have an interest in the submitted work. Other relationships: All authors have declared that there are no other relationships or activities that could appear to have influenced the submitted work.

\section{Acknowledgements}

The author would like to thank the deanship of scientific research for their support. And thanks to all medical staff in King Faisal Hospital and everyone participated in this study.

\section{References}

1. Lança T, Silva-Santos B: The split nature of tumor-infiltrating leukocytes: implications for cancer surveillance and immunotherapy. Oncoimmunology. 2012, 1:717-725. 10.4161/onci.20068

2. Chabot-Richards DS, George TI: Leukocytosis. Int J Lab Hematol. 2014, 36:279-288. 10.1111/ijlh.12212

3. Rupert J, Riley LK: Evaluation of patients with leukocytosis . Am Fam Physician. 2015, 92:1004-1011.

4. Cerny J, Rosmarin AG: Why does my patient have leukocytosis? Hematol Oncol Clin North Am. 2012, 26:303-319. 10.1016/j.hoc.2012.01.001

5. Granger JM, Kontoyiannis DP: Etiology and outcome of extreme leukocytosis in 758 nonhematologic cancer patients: a retrospective, single-institution study. Cancer. 2009, 115:3919-3923. 10.1002/cncr.24480

6. Stone SC, Rossetti RAM, Lima AM, Lepique AP: HPV associated tumor cells control tumor microenvironment and leukocytosis in experimental models. Immun Inflamm Dis. 2014, 2:63-75. 10.1002/iid3.21

7. Qiu MZ, Xu RH, Ruan DY, et al.: Incidence of anemia, leukocytosis, and thrombocytosis in patients with solid tumors in China. Tumor Biol. 2010, 31:633-641. 10.1007/s13277-010-0079-8

8. Kasuga I, Makino S, Kiyokawa H, Katoh H, Ebihara Y, Ohyashiki K: Tumor-related leukocytosis is linked with poor prognosis in patients with lung carcinoma. Cancer. 2001, 92:2399-2405. 10.1002/10970142(20011101)92:9<2399::aid-cncr1588>3.0.c0;2-w

9. Moghadamyeghaneh Z, Hanna MH, Carmichael JC, Mills SD, Pigazzi A, Stamos MJ: Preoperative leukocytosis in colorectal cancer patients. J Am Coll Surg. 2015, 221:207-214. 10.1016/j.jamcollsurg.2015.03.044

10. Schernberg A, Escande A, Del Campo ER, et al.: Leukocytosis and neutrophilia predicts outcome in anal cancer. Radiother Oncol. 2017, 122:137-145. 10.1016/j.radonc.2016.12.009

11. Connolly GC, Khorana AA, Kuderer NM, Culakova E, Francis CW, Lyman GH: Leukocytosis, thrombosis and early mortality in cancer patients initiating chemotherapy. Thromb Res. 2010, 126:113-118. 10.1016/j.thromres.2010.05.012

12. Moradi S, Jafarian Kerman SR, Rohani F, Salari F: Association between diabetes complications and leukocyte counts in Iranian patients. J Inflamm Res. 2012, 5:7-11. 10.2147/JIR.S26917

13. Chung FM, Tsai JCR, Chang DM, Shin SJ, Lee YJ: Peripheral total and differential leukocyte count in diabetic nephropathy: the relationship of plasma leptin to leukocytosis. Diabetes Care. 2005, 28:1710-1717. 10.2337/diacare.28.7.1710

14. Jiang H, Yan WH, Li CJ, Wang AP, Dou JT, Mu YM: Elevated white blood cell count is associated with higher risk of glucose metabolism disorders in middle-aged and elderly Chinese people. Int J Environ Res Public Health. 2014, 11:5497-5509. 10.3390/ijerph110505497

15. Shankar A, Wang JJ, Rochtchina E, Yu MC, Kefford R, Mitchell P: Association between circulating white blood cell count and cancer mortality: a population-based cohort study. Arch Intern Med. 2006, 166:188194. 10.1001/archinte.166.2.188

16. Margolin ML, Zeitlin N, Friedman YE, Globus O, Mouallem M: Eosinophilia and leukocytosis in a patient with lung cancer. Isr Med Assoc J. 2019, 21:58-59.

17. Park B, Lee HS, Lee JW, Park S: Association of white blood cell count with breast cancer burden varies according to menopausal status, body mass index, and hormone receptor status: a case-control study. Sci Rep. 2019, 9:5762. 10.1038/s41598-019-42234-6

18. Mun ST, Jang SH, Ryu A: Early stage ovarian carcinoma with symptoms mimicking tuberculous peritonitis in 


\section{Cureus}

a postmenopausal woman: a case report. Medicine. 2018, $97:$ :e12669. 10.1097/MD.0000000000012669

19. Zandberg DP, Bhargava R, Badin S, Cullen KJ: The role of human papillomavirus in nongenital cancers . CA Cancer J Clin. 2013, 63:57-81. 10.3322/caac.21167

20. Schernberg A, Blanchard P, Chargari C, et al.: Leukocytosis, prognosis biomarker in locally advanced head and neck cancer patients after chemoradiotherapy. Clin Transl Radiat Oncol. 2018, 12:8-15.

10.1016/j.ctro.2018.07.002

21. Garcia-Arias A, Cetina L, Candelaria M, Robles E, Dueñas-González A: The prognostic significance of leukocytosis in cervical cancer. Int J Gynecol Cancer. 2007, 17:465-470. 10.1111/j.1525-1438.2007.00816.x

22. Tavares-Murta BM, Mendonça MAO, Duarte NL, da Silva JA, Mutão TS, Garcia CB, Murta EFC: Systemic leukocyte alterations are associated with invasive uterine cervical cancer. Int J Gynecol Cancer. 2010, 20:1154-1159. 10.1111/IGC.0b013e3181ef8deb

23. Worley MJ, Nitschmann CC, Shoni M, Vitonis AF, Rauh-Hain AJ, Feltmate CM: The significance of preoperative leukocytosis in endometrial carcinoma. Gynecol Oncol. 2012, 125:561-565. 10.1016/j.ygyno.2012.03.043 